\title{
Sulfated Zirconia Catalysts for Low Temperature Isomerization of n-Pentane
}

\author{
A. K. Aboul-Gheit, D. S. El-Desouki, S. M. Abdel-Hamid, S. \\ A. Ghoneim, A. H. Ibrahim and F.K. Gad* \\ Process Development Division, Egyptian Petroleum Research \\ Institute, Cairo and *Faculty of Petroleum and Minerals \\ Engineering Suez Canal University, Egypt.
}

\begin{abstract}
T NCONVENTIONAL sulphated zirconia (SZ) catalysts were prepared and examined for n-pentane isomerisation in this investigation. The sulfation was performed using $\mathrm{H}_{2} \mathrm{SO}_{4}$ acid. The calcination step seems to attain the highest influence using our sol-gel preparations, where the crystallinity transforms to the denser form. However, the surface properties do not exhibit such effectiveness. Calcination at $500^{\circ} \mathrm{C}$ gives the best activities and stabilities, whereas at $650^{\circ} \mathrm{C}$, calcination is deteriorative. IR spectra, TPR, TGA, DSC, $\mathrm{XRD}$ and surface properties of the current catalysts were investigated.
\end{abstract}

Keywords: Zirconium sulphate, Hydroisomerization, n-Pentane, Super acids, Sulfation and Sol-gel.

Producing gasoline of high octane number via hydroisomerization of light paraffins is an important industrial process ${ }^{(1)}$. The isomerization is carried out on catalysts such as halogenated alumina, which is highly corrosive, or on acidic zeolites $^{(2-8)}$ which require higher reaction temperatures ${ }^{(9-10)}$. In order to achieve maximum isomer yields at low temperatures, a new generation of friendly catalysts with high activities at low reaction temperatures and high selectivity to isomers is a very important target. In the last decades, it was found that sulphated oxides such as $\mathrm{ZrO}_{2}, \mathrm{TiO}_{2}, \mathrm{SnO}_{2}, \mathrm{Fe}_{2} \mathrm{O}_{3}$ and $\mathrm{HfO}_{2}$ have high surface acidity and activity at very low temperatures ${ }^{(11)}$. Among the super acid catalysts, sulfated zirconia (SZ) has proved to acquire the highest activity which is related mainly to its strong Brönsted and Lewis acid sites ${ }^{(12-17)}$. It has been applied to various reactions such as isomerization, alkylation, acylation, esterification, etherification, condensation, nitration and cyclization ${ }^{(18-20)}$ and has a large surface area compared with pure zirconia. $\mathrm{H}_{2}$ plays an important role in the hydroisomerization, it is responsible for forming the secondry n-alkyl cation which is a main step of skeletal isomerisation ${ }^{(21)}$. Other authors; Tichit et al. ${ }^{(22)}$ and Signoretto et al. ${ }^{(23)}$ used $\mathrm{H}_{2}$ flow in the isomerisation of n-hexane and $\mathrm{n}$ butane, respectively.

The properties of sulfated zirconia (SZ) depend on many factors such as the nature of the precursors used, preparation conditions like sulfating method, calcination temperature ${ }^{(24)}$, sulphur species, surface area and water content ${ }^{(25)}$. Sulfated zirconia is considered as heterogeneous catalyst, as it is composed of amourphous sulphate phase $(\mathrm{S})$ and crystalline zirconia phase $\left(\mathrm{ZrO}_{2}\right)$. Pure $\mathrm{ZrO}_{2}$ 
exists in three types of crystalline structures: tetragonal, monoclinic and cubic. Among various preparation techniques of $\mathrm{SZ}^{(26-28)}$ in sol-gel preparation method tetragonal phase is stable and transformed into monoclinic via thermal treatment. Zhao et al. ${ }^{(29)}$ and Stichert et $a .^{(30)}$ found that the monoclinic sulfated zirconia is less effective compared to tetragonal sulfated zirconia for n-butane and npentane isomerization. Moreover, Haase and Sauer ${ }^{(31)}$ suggested that the most stable configurations of sulfur species on the surface of tetragonal zirconia are the tridentate sulphate anion and the $-\mathrm{SO}_{3}$ complex ${ }^{(32)}$. In the present work, we prepared SZ via simple sol gel method in one step including sulfation for $\mathrm{n}$ pentane isomerization ${ }^{(22-33)}$.

\section{Experimental}

Preparation of the catalysts

Preparation of the catalysts has been carried out according to a modified method by Tichit et al. ${ }^{(22)}$. $10 \mathrm{~cm}^{3}$ of zirconium isopropoxide $(70 \%)$ in $12.5 \mathrm{~cm}^{3}$ isopropanol (99\%) was mixed slowly with $0.25 \mathrm{~cm}^{3} \mathrm{H}_{2} \mathrm{SO}_{4}(96 \%)$. The mixture was placed in a conical flask and stirred for $30 \mathrm{~min}$ at room temperature. The weight ratio of $\mathrm{Zr}: \mathrm{S}$ was 1:0.038. A solution of $30 \mathrm{~cm}^{3}$ isopropanol in $1.6 \mathrm{~cm}^{3}$ $\mathrm{H}_{2} \mathrm{O}$ was added dropwise with stirring to carry out the hydrolysis and gelation. The gel was aged for $1 \mathrm{hr}$ at room temperature then dried for $12 \mathrm{hr}$ at $120^{\circ} \mathrm{C}$. The dried gel was divided into four parts which were calcined at temperatures 500 , 550, 600 and $650^{\circ} \mathrm{C}$ and named SZ500, SZ550, SZ600 and SZ650, respectively. Figure 1 illustrates the steps of catalysts preparation.

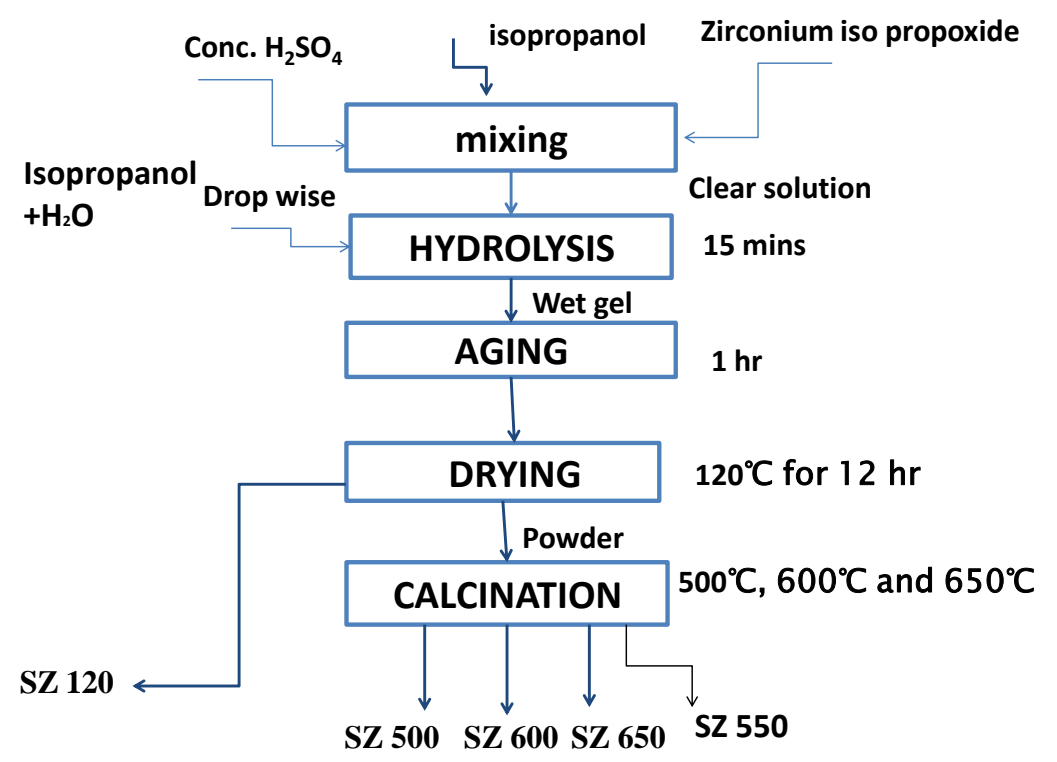

Fig. 1. Preparation of SZ using sol-gel method. 


\section{Characterization of the catalysts}

$X$-ray diffraction analysis $(X R D)$

All samples were characterized using powder XRD for crystallinity and phase content in the solid materials, using Analytical \{X'PERT PROMPD\} Xray diffractometer, $\mathrm{Cu} \mathrm{K} \alpha$ radiation of wavelength $\lambda=1.5406 \AA$, rating of $40 \mathrm{KV}$, $40 \mathrm{~mA}$, step size $=0.02$ and scan step time of $0.4 \mathrm{sec}$. The catalyst powder $1 \mathrm{~cm} \times 2.5 \mathrm{~cm} \times 1 \mathrm{~mm}$ trough while maintaining uniform layer thickness.

\section{Transmission electron microscopic analysis (TEM)}

Amorphous and crystalline samples were imaged by JEM-2100F TEM which is next generation TEM that simplifies atomic level structural analyses. The samples were sonicated for $20 \mathrm{~min}$.

\section{BET surface analysis}

Isothermal nitrogen adsorption / desorption method was used to estimate specific surface areas and pore size distribution of the prepared sulfated zirconia (SZ) samples using the BET method. The BJH method was applied for calculating the pore size distribution in the catalyst. These parameters were determined using Quanta chrome Nova 3200, commercial BET unit at $78^{\circ} \mathrm{K}$ using liquid $\mathrm{N}_{2}$. Prior to the measurement, the samples were out gassed in a stream of $30 \% \mathrm{~N}_{2} / \mathrm{He}$ mixture while being heated to $200^{\circ} \mathrm{C}$ for $3 \mathrm{hr}$ under a reduced pressure of $10-5$ Torr to remove all adsorbed moisture from the catalyst surface.

\section{Temperature programmed reduction analysis (TPR)}

TPR for the current samples was investigated using CHEM-BET 3000 TPR instrument containing TCD detector. Prior to reduction, the catalysts (ca $0.2 \mathrm{~g}$ ) were heated at a rate of $20^{\circ} \mathrm{C} / \mathrm{min}$ up to $400^{\circ} \mathrm{C}$, and kept for $2 \mathrm{hr}$ at that temperature under a $\mathrm{He}$ flow. The catalyst was then cooled to ambient temperature in $\mathrm{He}$ flow, then reduced in flowing gas containing $10 \% \mathrm{H}_{2}$ in $\mathrm{Ar}$ at a total flow rate of $50 \mathrm{~cm}^{3} / \mathrm{min}$ and finally heated at a rate of $10{ }^{\circ} \mathrm{C} / \mathrm{min}$ to reach $1000^{\circ} \mathrm{C}$. Profiles of the samples show $\mathrm{H}_{2}$ consumption and estimate the reduction behaviour of the catalysts.

Thermal analysis

TGA for the samples showed the weight loss as a function of temperature. DSC gives the heat flow either endothermic or exothermic. Both analyses were carried out simultaneously on SDT Q600 with a heating rate of $10 \mathrm{~K} / \mathrm{min}$ from room temperature to $1073 \mathrm{~K}$ in $\mathrm{N}_{2}$ as inert gas.

FT-IR spectral analysis

The Nicolet iS10 FT-IR spectrometer was employed to measure the functional groups presented in the catalysts appearing at different frequencies $\left(\mathrm{cm}^{-1}\right)$. 


\section{Catalytic reaction}

The prepared catalysts were tested for n-pentane isomerisation applying a pulse catalytic reactor[ $(6 \mathrm{~mm}$ internal diameter $) \times 10 \mathrm{~cm}]$, placed at the injection port of a GC where the reaction was performed. The reactor was packed with $0.2 \mathrm{~g}$ of a catalyst powder. The effluent from the reactor was analysed using OV 101 column directly connected to the outlet of the reactor. A constant flow of $20 \mathrm{~cm}^{3} / \mathrm{min} \mathrm{H}_{2}$ was applied. and $1 \mu \mathrm{l}$ pulses of $\mathrm{n}$-pentane were injected. Prior to applying the current catalytic test, the catalyst has to be activated according to the following steps:

- Preheating the catalyst at $120^{\circ} \mathrm{C}$ for $4 \mathrm{hr}$ in static air.

- Charging the reactor with the powdered catalyst and kept heated at $450^{\circ} \mathrm{C}$ in a stream of $\mathrm{N}_{2}$ for $3 \mathrm{hr}$.

Isomerization Selectivity of the catalyst $=$ Isopentane $\times 100 /$ n-pentane converted.

\section{Results and Discussion}

\section{$X$-ray Diffraction $(X R D)$}

Figure 2 represents the XRD patterns of the prepared samples. It shows that, the catalyst dried at $120^{\circ} \mathrm{C}$ and calcined at 500 and $550^{\circ} \mathrm{C}$ give significantly amorphous agglomerates which are attributed to the presence of amorphous sulphate that has been highly dispersed in the matrix. Also, Platero et al. ${ }^{[34]} \mathrm{did}$ not obtain any diffraction peaks for zirconia in zirconium sulphate calcined at $400^{\circ} \mathrm{C}$ due to the high hygroscopic nature of sulphated ions.

Characteristic peaks of monoclinic phase appear as calcination temperature increases, whereas the tetragonal phase decreases in the SZ650 catalyst which contains both monoclinic and tetragonal phases. These results agree with Prasetyoko et al $^{(35)}$ and Cornelli et al. ${ }^{(36)}$ suggested that transformation of tetragonal to monoclinic phases occurs at temperatures above $500^{\circ} \mathrm{C}$ for zirconia containing sulphate.

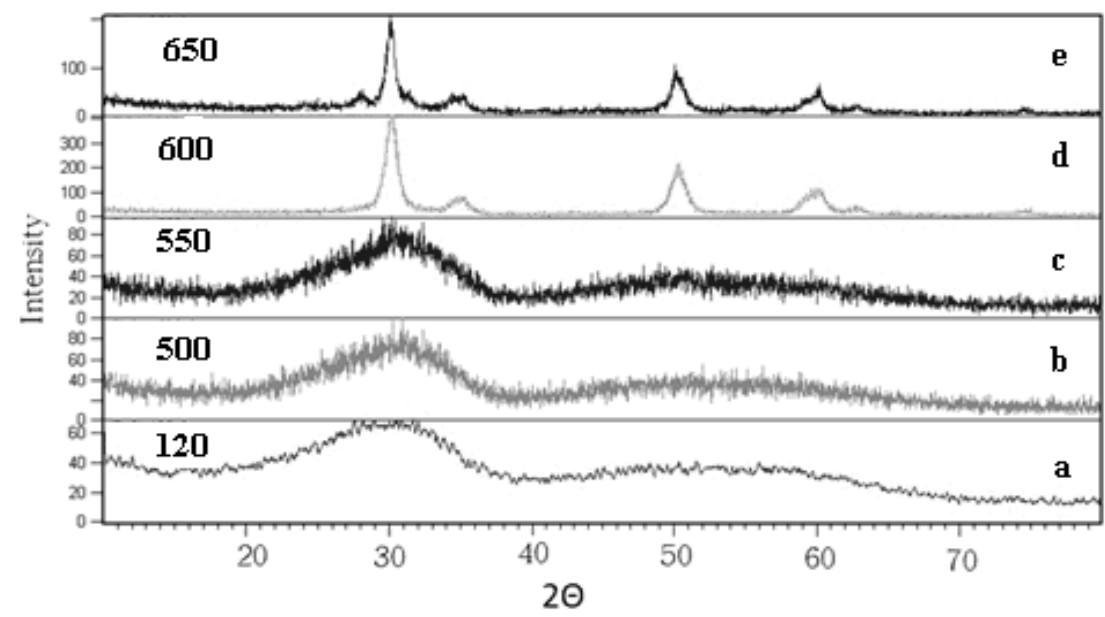

Fig. 2. XRD patterns of SZ catalyst calcined at different temperatures.

Egypt. J. Chem. 55, No. 5 (2012) 
Applying the Scherrer's equation

$$
\mathrm{D}=\mathrm{K} \lambda / \beta \cos \theta
$$

Where :

$\mathrm{D}$ is the average crystallite diameter.

$\mathrm{K}$ is the shape factor.

$\Theta$ is the half of position angle $\{$ Bragg angle $\}$.

$\beta$ is the full width of half maximum FWHM of the main peak in radians.

$K$ is the wave length of X-ray.

The average crystallite size has been estimated and found to be equal to 11.3 and $16.6 \mathrm{~nm}$ for the catalysts calcined at 600 and $650^{\circ} \mathrm{C}$, respectively.

The fractional XRD peak area of the monoclinic phase relative to that of the tetragonal phase has been calculated according to Equation (1):

$$
f_{m} \quad=100\left(\frac{I_{m}(111)+I_{m}(\overline{1} 11)}{I_{m}(111)+I_{m}(\overline{1} 11)+I_{f}(111)}\right)
$$

where $I_{\mathrm{t}}(111)$ is the XRD sity of the tetragonal phase peak at $2 \theta=30.3^{\circ}, \mathrm{Im}$ (I11) and $\operatorname{Im}(111)$ are the XRD intensity of the monoclinic phase peak at $2 \theta=$ $28.6^{\circ}$ and $31.8^{\circ}$, respectively.

TABLE 1. Intensity values for monoclinic and tetragonal phases taken from XRD data.

\begin{tabular}{|c|c|c|}
\hline Peak & Intensity at $\mathbf{T c}=\mathbf{6 0 0}^{\circ} \mathbf{C}$ & Intensity at $\mathbf{T c}=\mathbf{6 5 0}^{\circ} \mathbf{C}$ \\
\hline $\operatorname{Im} 111$ & 15.2 & 8.31 \\
\hline $\operatorname{Im} \overline{\mathrm{I}} 11$ & 0 & 11.92 \\
\hline$I_{\mathrm{t}} 111$ & 100 & 100 \\
\hline
\end{tabular}

Applying Equation (1), the area ratio for monoclinic phase related to monoclinic plus tetragonal phases has been calculated.

The intensity fraction of monoclinic phase at $\mathrm{T}_{\mathrm{c}}=600^{\circ} \mathrm{C}$ amounts to $13.2 \%$ and amounts to $16.2 \%$ at $\mathrm{T}_{\mathrm{c}}=650^{\circ} \mathrm{C}$. To calculate the mass fraction, the relation between wt $\%$ of each phase and intensity ratio (calibration curve) must be used according to the' Rieveld method' [H\&M Analytical Services]. The increase of the monoclinic phase intensity is an indication of the phase transformation resulting by increasing the calcination temperature. Other authors observed that $\mathrm{ZrO}_{2}$ appears at $600^{\circ} \mathrm{C}$ in case of tetragonal, monoclinic and cubic phases ${ }^{(34,37)}$. The SZ transition temperature from the amorphous to tetragonal phase was $\sim 150^{\circ} \mathrm{C}$ higher than that of pure $\mathrm{ZrO}_{2}$. X-ray diffraction data indicated a 
tetragonal phase of $\mathrm{ZrO}_{2}$ at temperatures between 500 and $600^{\circ} \mathrm{C}$, whereas a twophase mixture of tetragonal and monoclinic $\mathrm{ZrO}_{2}$ is formed at $700^{\circ} \mathrm{C}$. The authors assumed that the interaction between zirconium sulfate and $\mathrm{ZrO}_{2}$ hinders the transition of $\mathrm{ZrO}_{2}$ from amorphous to tetragonal phase ${ }^{(38)}$.

The crystalline phase of zirconium sulphate was not observed at any calcination temperature, indicating that most of zirconium sulfate is present as an amorphous form and/ or well dispersed on the surface of zirconia.

\section{Transmission electron microscope (TEM)}

TEM of the samples calcined at 500,600 and $650^{\circ} \mathrm{C}$ for $3 \mathrm{hr}$ is shown in Fig. 3. The figure indicates the presence of zirconia crystals $\left(\mathrm{ZrO}_{2}\right)$ in amorphous low density matrix forming heterogeneous nature as supported by the finding of Sarzanini et al. $1995^{(39)}$ The crystallinity of zirconia increases as the calcination temperature increases whereby amorphous sulphate still exists and the crystallinity of zirconia is not completed. The true crystal sizes range between 4 and $8 \mathrm{~nm}$ at $600^{\circ} \mathrm{C}$ and between 8 and $13 \mathrm{~nm}$ at $650^{\circ} \mathrm{C}$.
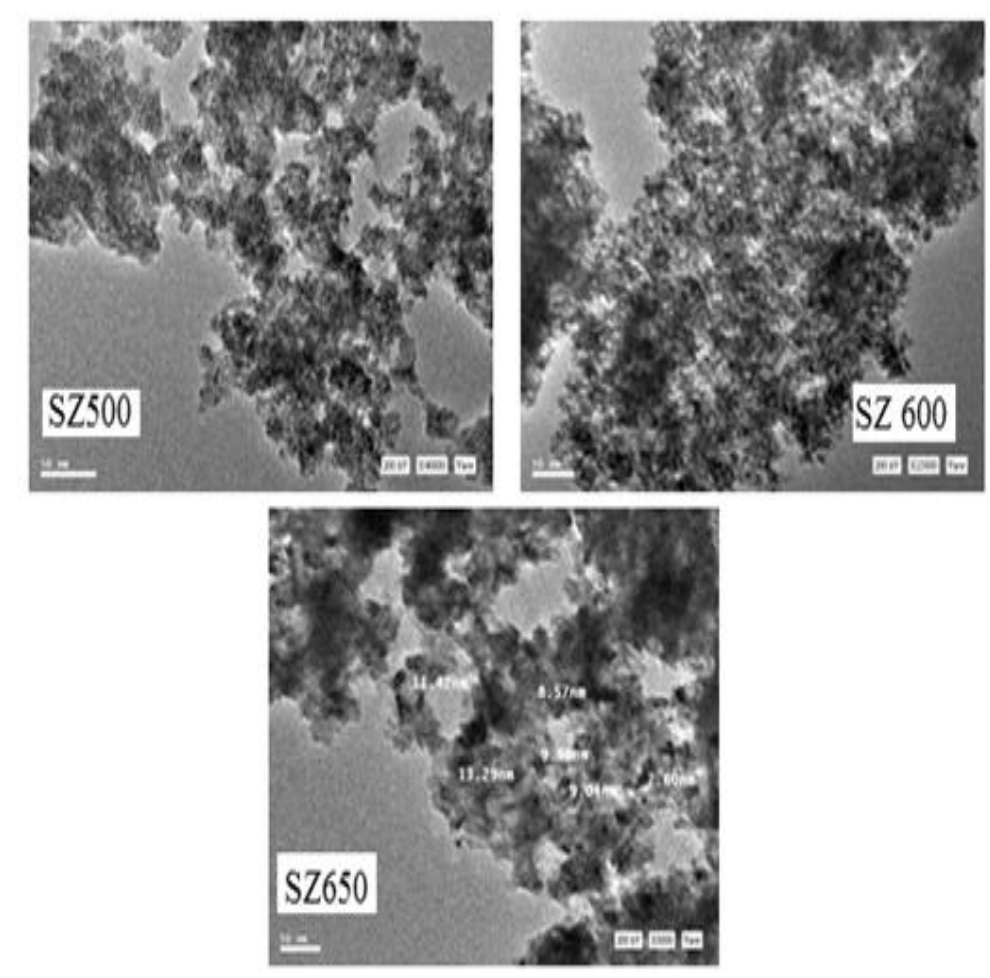

Fig. 3. TEM images of sulphated zirconia samples at different calcination temperatures.

Egypt. J. Chem. 55, No. 5 (2012) 


\section{$\mathrm{N}_{2}$ adsorption - desorption isotherms and pore size distribution}

Table 2 shows the BET specific surface area and pore volume of the prepared catalysts. The sample dried at $120^{\circ} \mathrm{C}$ exhibits the largest specific surface area $\left(219 \mathrm{~m}^{2} / \mathrm{g}\right)$ and largest pore volume $\left(0.43 \mathrm{~cm}^{3} / \mathrm{g}\right)$. The SZ sample calcinated at $500^{\circ} \mathrm{C}$ gives a lower surface area $\left(135 \mathrm{~m}^{2} / \mathrm{g}\right)$ and lower pore volume $\left(0.371 \mathrm{~cm}^{3} / \mathrm{g}\right)$. Further, increase of calcination temperature to 550,600 and $650^{\circ} \mathrm{C}$ gives successively decreasing values of specific surface area and pore volume to $57 \mathrm{~m}^{2} / \mathrm{g}$ and $0.124 \mathrm{~cm}^{3} / \mathrm{g}$, respectively. This decrease in specific surface area and pore volume of the catalysts is attributed to the phase transformation from tetragonal to the denser monoclinic phase ${ }^{(40)}$ associated with migration and agglomeration of the particles. This effect is more evident through increasing temperature from 600 to $650^{\circ} \mathrm{C}$.

TABLE. 2. Physical and surface properties of SZ samples thermally treated at different Temperatures.

\begin{tabular}{|c|c|c|c|c|c|}
\hline Temp. ${ }^{\circ} \mathbf{C}$ & $\mathbf{1 2 0}$ & $\mathbf{5 0 0}$ & $\mathbf{5 5 0}$ & $\mathbf{6 0 0}$ & $\mathbf{6 5 0}$ \\
\hline $\begin{array}{c}\text { Surface area } \\
\mathbf{m}^{2} / \mathbf{g}\end{array}$ & 219 & 135 & 109 & 98 & 57 \\
\hline $\begin{array}{c}\text { Pore volume } \\
\mathbf{c c} / \mathbf{g}\end{array}$ & 0.431 & 0.371 & 0.321 & 0.291 & 0.124 \\
\hline $\begin{array}{c}\text { Crystal size } \\
\mathbf{n m}\end{array}$ & --- & --- & --- & 11.3 & 18.6 \\
\hline \begin{tabular}{c} 
Crystallinity \\
\hline
\end{tabular} & amorphous & amorphous & amorphous & crystalline & $\begin{array}{c}\text { High } \\
\text { crystalline }\end{array}$ \\
\hline
\end{tabular}

The $\mathrm{N}_{2}$ adsorption-desorption isotherms obtained for the current $S Z$ catalysts are illustrated in Fig. 4. The isotherms belong to Type IV associated with hysteresis loop of type $\mathrm{H} 3$ in all catalysts ${ }^{(35)}$.

The adsorption capacity decreases as the calcination temperature increases, due to surface area decreases of the catalysts. This agrees with surface area data in Table 2. Also, the sharp increase in isotherm after $\mathrm{P} / \mathrm{Po} \approx 0.8$ is due to the capillary condensation in large range of mesopores. Moreover, the hysteresis loops (H3) can be said to indicate the presence of plates or slits pore shape (Fig. 4).

Figure 5 shows that the Pore size distribution calculated according to the BJH method gives important variations. The dried catalyst (SZ120) exhibits the largest presence of micropores among the other current catalysts. However, the pore size distribution of SZ500 and SZ600 catalysts shows close features except for acquiring some micropores $(9-16 \mathrm{~nm})$ in case of the SZ500 catalyst. On the other hand, the SZ650 catalyst shows low distribution of the pores during the whole range indicating that calcination at $650^{\circ} \mathrm{C}$ is deteriorative for the majority 
of the pores. This indicates higher loss of smaller pores on calcination as temperature increases from 500 to $650^{\circ} \mathrm{C}$.
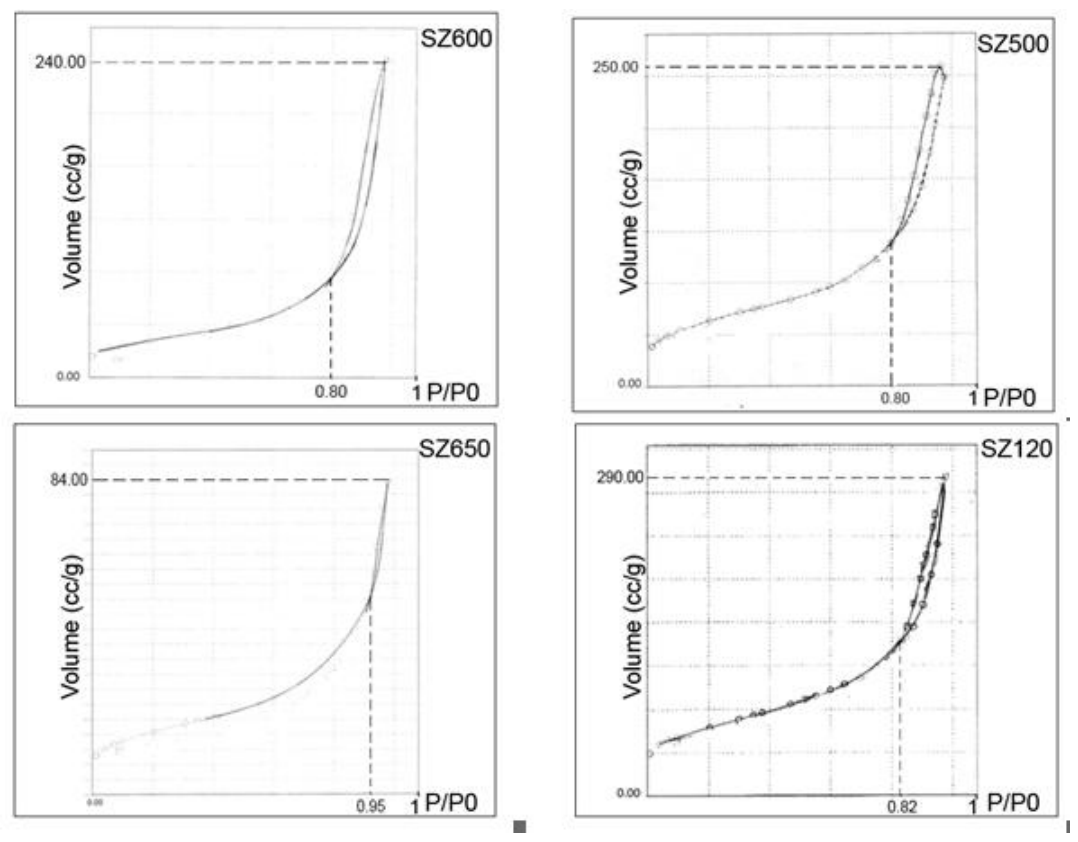

Fig. 4. Isothermas at different calcination temperatures.

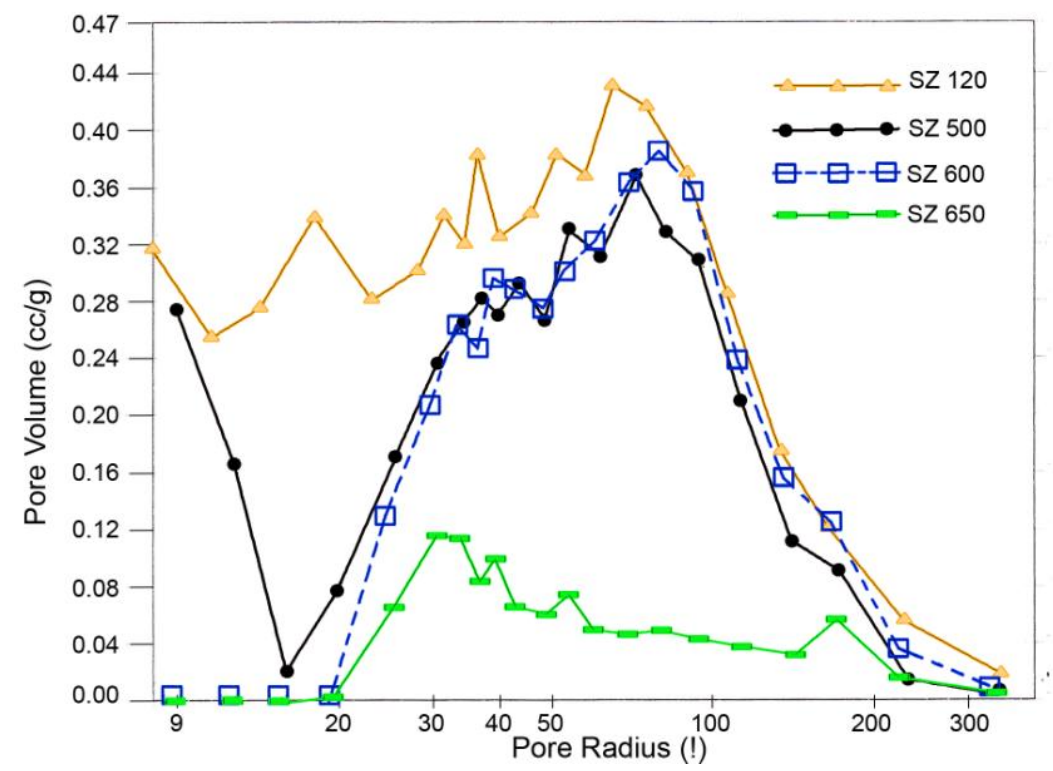

Fig. 5. Pore size distribution of SZ samples.

Egypt. J. Chem. 55, No. 5 (2012) 


\section{Infrared (IR) spectroscopy}

Figure 6 shows the IR spectra for the current sulphated zirconia samples: SZ120, SZ500, SZ600 and SZ650. In the $\mathrm{OH}$ region (between 4000 and $3300 \mathrm{~cm}^{-1}$ ), the sample dried at 120 (SZ120) shows a broad intense band at $3000-3600 \mathrm{~cm}^{-1}$ maximized at $3450 \mathrm{~cm}^{-1}$. The intensity of this band decreases with increasing the calcination temperature. The decrease of high frequency $\mathrm{O}-\mathrm{H}$ bands can be due to the reduction of sulphate groups that preferentially occupy the terminal position rather than bridged $\mathrm{OH}$ of $\mathrm{ZrO}_{2}{ }^{(13)}$. The shift to lower frequency of the $\mathrm{OH}$ stretching frequency $\left(3410 \mathrm{~cm}^{-1}\right)$ is a result of the inductive effect from the neighbouring sulphate group ${ }^{(41)}$. There appears a very small peak at $3668 \mathrm{~cm}^{-1}$ assigned to bridged $\mathrm{OH}-\mathrm{Zr}$ groups. Also, for $\mathrm{SZ}$ that was prepared by impregnation ${ }^{(42)}$ of hydrous gel with $\mathrm{H}_{2} \mathrm{SO}_{4}$, similar IR spectra showing two O-H stretching bands at $3635 \mathrm{~cm}^{-1}$ and $3655 \mathrm{~cm}^{-1}$. Moreover, the spectra in Fig.6 show band at $1630 \mathrm{~cm}^{-1}$ corresponding to the $\mathrm{H}_{2} \mathrm{O}$ bending mode ${ }^{(34)}$. Calcination at $500^{\circ} \mathrm{C}$ results in partial elimination of adsorbed water which increases as calcination temperature increases. In SZ120 there are two bands appearing at ca.1462 and $1350 \mathrm{~cm}^{-1}$ which represent $\mathrm{S}=\mathrm{O}$ stretching of disulfate and monosulfate species, respectively ${ }^{(43)}$. These bands disappeared in the spectra of SZ500, SZ600 and SZ650 due to the high thermal decomposition of sulphate ${ }^{(44)}$. The IR spectrum in the region from ca. $1200-995 \mathrm{~cm}^{-1}$ is assigned to bidentate sulfate ion coordinated to the $\mathrm{Zr}^{4+(45,38,46)}$. This suggests that calcination at temperaturs of 500,600 and $650^{\circ} \mathrm{C}$ causes high decomposition of sulfate ion in the samples.

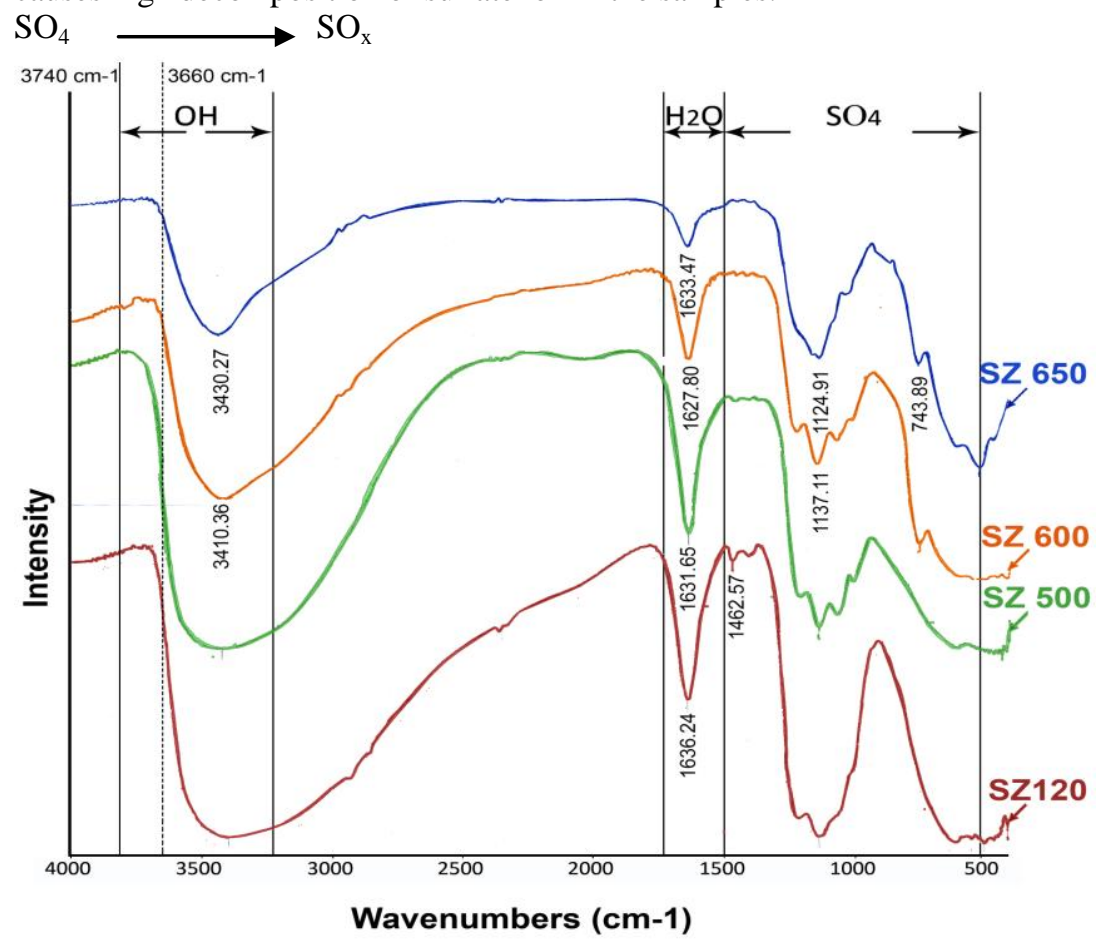

Fig. 6. IR spectra of SZ samples. 
There is a gradual decrease of both $\mathrm{OH}$ and $\mathrm{H}_{2} \mathrm{O}$ absorbances via increasing the calcination temperature from $120^{\circ} \mathrm{C}$ to $500^{\circ} \mathrm{C}$, beyond which a further increase of calcination temperature from $500^{\circ} \mathrm{C}$ to $650^{\circ} \mathrm{C}$.

\section{Thermal analysis}

The DSC thermogram obtained for the sample dried at $120^{\circ} \mathrm{C}$ overnight (SZ120). Fig.7 gives an obvious DSC endothermic effect ending at $180^{\circ} \mathrm{C}$ indicating the loss of physically adsorbed water on external surface of the sample. There appears another endothermic low intensity peak at $300^{\circ} \mathrm{C}$ corresponding to weight loss of about $10 \%$, and can be attributed to dehydroxylation process. Increasing the temperature to $550^{\circ} \mathrm{C}$, the sample shows an endothermic peak attributed to evolution of $\mathrm{SO}_{3}{ }^{(47-49)}$. This DSC effect corresponds to a small weight loss $\approx 3 \%$. (Fig. 7b). Both DSC and TGA curves obtained for SZ500 exhibit endothermic effects ending at $200^{\circ} \mathrm{C}$ corresponding to weight loss of $10 \%\left(100-90^{\circ} \mathrm{C}\right)$. The course of reactions between 200 and $600^{\circ} \mathrm{C}$ show insignificant thermal and weight loss effects till $625^{\circ} \mathrm{C}$. At $650^{\circ} \mathrm{C}$, an endothermic peak starts to appear and reaches a maximum at $680^{\circ} \mathrm{C}$. The endothermic effect of this stage arises from the decomposition of the sulphate ion to $\mathrm{SO}_{3}$ ion. Figure 8 shows the curves of TGA and DSC of SZ600 and SZ650 that exhibits a similarity to the SZ500 curve with a difference in lowering the DSC thermal effect at the higher calcinations temperature of the different samples. This is particularly evident in SZ650 graph where the endo/exothermic DSC peaks at higher temperature disappears $(50,51)$

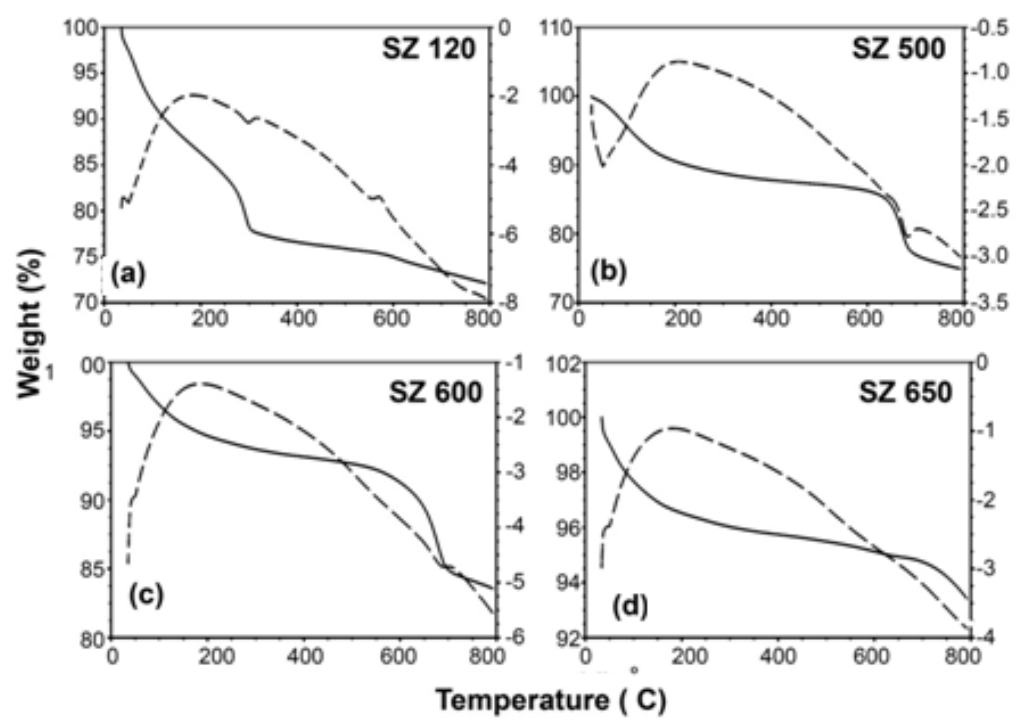

Fig. 7. Thermal analysis patterns: (a) TGA curves, (b) DSC curves of SZ samples. 


\section{Temperature programmed reduction (TPR)}

The reduction behaviour of the catalysts was determined by the TPR technique (Fig. 8). In Fig. 8 as shown there is no indication of $\mathrm{H}_{2}$ consumption for all SZ samples. For all sulfated zirconia catalysts, there is no indication of $\mathrm{H}_{2}$ consumption at temperatures below $550^{\circ} \mathrm{C}^{(40)}$. From TPR profiles, there is a broad peak starting from 550 to $620^{\circ} \mathrm{C}$ which decreases significantly as the calcination temperature increases. According to Vera et al. $2002^{(52)}$, this peak is attributed to the elimination of surface lattice oxygen and the reduction of $\mathrm{Zr}^{4+}$ to $\mathrm{Zr}^{3+}$ on the catalyst surface. Also, the release of sulfate from the surface of sulfated zirconia. This decrease in the peak intensity agrees with the decrease of surface area. Double reduction peaks are shown at $650-700^{\circ} \mathrm{C}$ and at $700-800^{\circ} \mathrm{C}$. Many investigators have reported that the high temperature TPR peaks are attributed to the reduction of sulfate species to sulfur dioxide and hydrogen sulfide ${ }^{(53,54)}$.

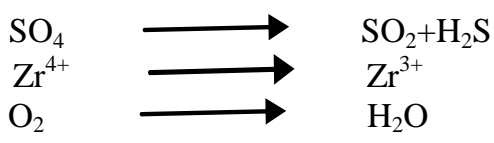

From the amount of hydrogen consumed, the intensity of the peak is unchanged from SZ120 to SZ500 and then decreases gradually from SZ500 to SZ650. This means that SZ500 still has the same amount of sulphate as sZ120.

The surface area of SZ500 is lower than SZ120 (Table 2) but the hydrogen consumed is the same. This is may be due to the reduction of the sulphate on the surface only without affecting the sulphate in the bulk (good dispersion).

In Fig. 8 the SZ650 TPR curve gives a significant peak at relatively much higher temperature than the SZ120, SZ500 and SZ600 catalysts $\left(750-850^{\circ} \mathrm{C}\right)$. This higher temperature shift is to be attributed to suffering more significant diffusion restriction caused by migration of the catalytic materials thus forming narrower pores. This is supported by acquiring a total pore volume of $0.124 \mathrm{cc} / \mathrm{g}$ and a surface area of $57 \mathrm{~m}^{2} / \mathrm{g}$ by the $S Z 650$ catalyst compared to $0.291 \mathrm{cc} / \mathrm{g}$ and $98 \mathrm{~m}^{2} / \mathrm{g}$, respectively, by the SZ500 catalyst.

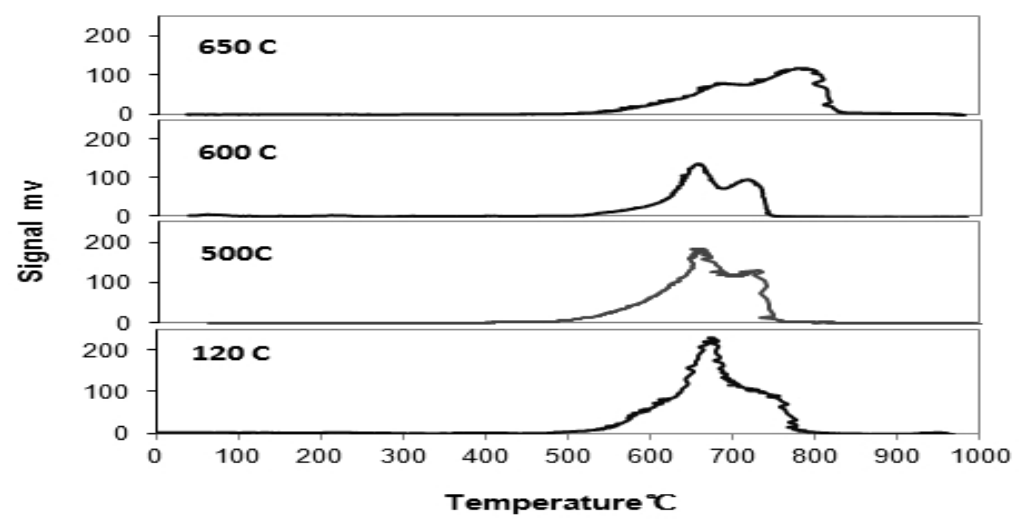

Fig. 8. $\mathrm{H}_{2}$ TPR curves of SZ samples.

Egypt. J. Chem. 55, No. 5 (2012) 
Catalytic activity test

Figure 9 shows that the calcination temperature is of critical influence for the activation of the SZ catalyst. Evidently, a temperature of $500^{\circ} \mathrm{C}$ can be considered the calcination temperature of choice since it gives a complete isomerization at a wide range of low reaction temperatures $\left(30-90^{\circ} \mathrm{C}\right)$, which indicates high stability of performance and economic privilege compared to using catalysts SZ600 and SZ650. These later versions reach their maximum isomerisation activities only at 175 and $40^{\circ} \mathrm{C}$, respectively.

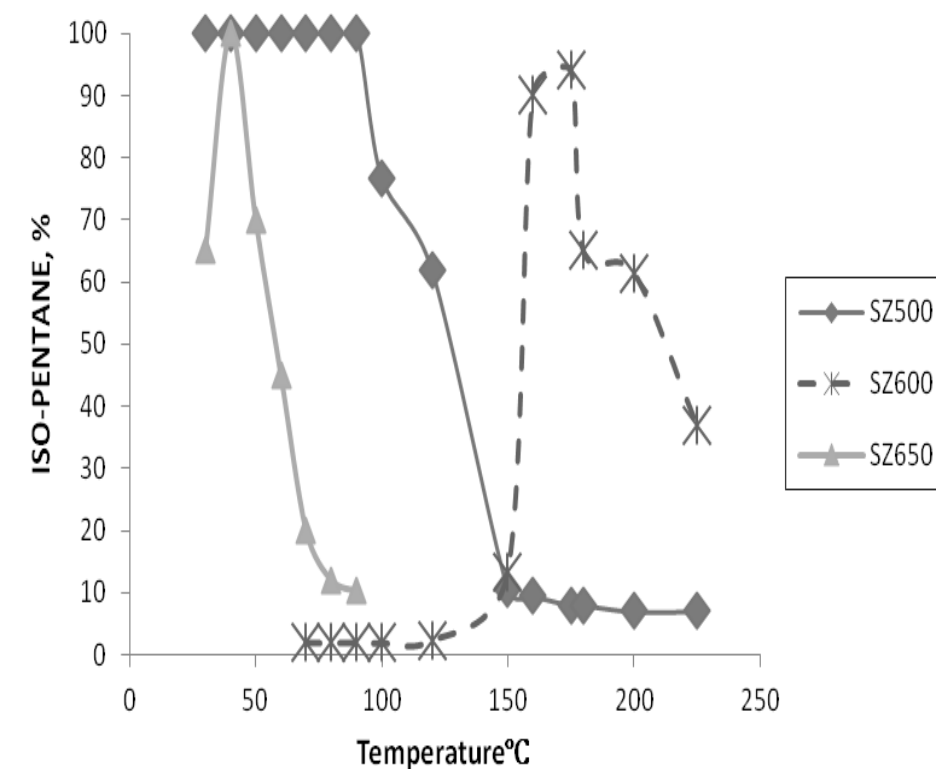

Fig. 9. Selectivity for isopentane using the current catalysts.

Time on stream test

Figures (10a) shows that the activity of the SZ500 catalyst sample is completely unaffected till the $9^{\text {th }}$ injection at $100 \%$, beyond which the decline of activity takes place more gradually reaching 55\% after 17 injections. Figure (10b) also shows that the thermal stability of the SZ600 sample is continued till the $3^{\text {rd }}$ injection only, beyond which the catalyst acquires lower stability during 4 injections followed by a faster drop till becomes inactive at the $8^{\text {th }}$ injection. It is to be noticed that the volume of one n-pentane injection is $1 \mu l$ throughout this study.

Egypt. J. Chem. 55, No. 5 (2012) 

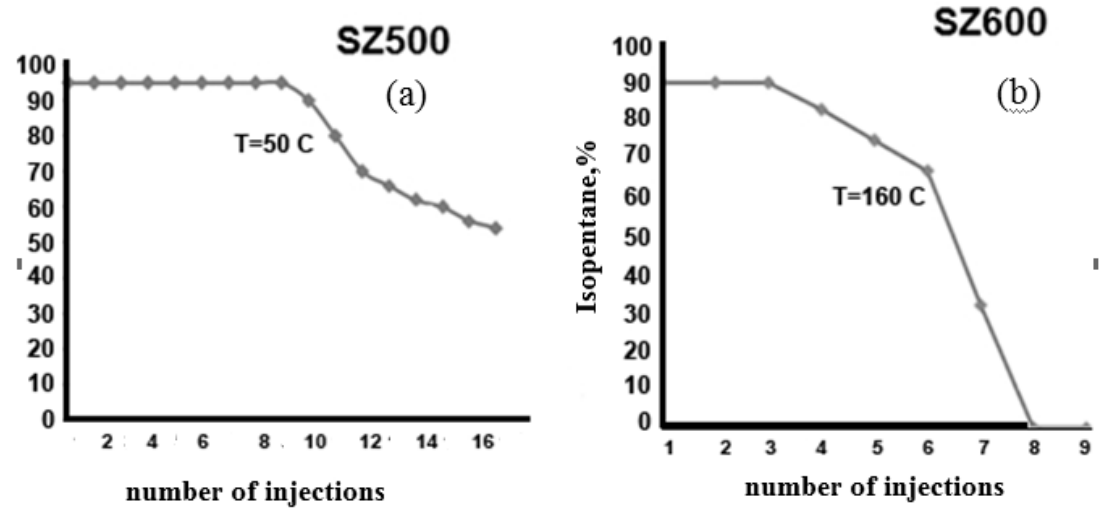

Fig. 10. Iso-pentane production as a function of injection numbers.

The sulphur content in the calcined sample of SZ was slightly lower after carrying out the n-pentane isomerisation reaction since this reaction has been carried out at relatively low temperatures compared to those used in presence of conventional isomerisation catalysts. The sharp deactivation of SZ is the major disadvantage of this catalyst ${ }^{(55-57)}$, this action may be attributed to coke formation after certain number of $n$-pentane pulses.

\section{Conclusion}

The highly difficult reducibility of the SZ650 catalyst has evidently contributed to its lower activity for n-pentane isomerisation, whereas the optimum activity is acquired by the SZ500 version which retains highest $\mathrm{OH}$ and $\mathrm{Zr}^{3+}$. The calcined SZ500 catalyst is $100 \%$ active at reaction temperatures between 30 and $90^{\circ} \mathrm{C}$, whereas the SZ600 gives maximum isomerisation of $94 \%$ at $175^{\circ} \mathrm{C}$. On the contrary, the SZ650 gives this maximum at $40^{\circ} \mathrm{C}$. The SZ500 catalyst is the most stable since it acquires $100 \%$ activity and selectivity during a broad reaction temperature region. From economic point of view, the SZ500 catalyst can be safely considered the optimum.

\section{References}

1. Chica, A., Corma, A. and Miguel, Isomerisation of C5-C7 n-alkanes on unidirectional large pore zeolites: activity, selectivity and adsorption features. J. Catal. Today, $\mathbf{6 5}$, 101 (2001).

2. Aboul-Gheit, A. K., Awadallah, A. E., El-Desouki, D. S. and Aboul-Gheit, N.A.K., n-Pentane hydroconversion using Pt-loaded zeolite catalysts. Petroleum Science and Technology, 27, 2085 (2009). 
3. Ali, Laila, I., Ali, A.A., Aboul-Fotouh, S. M. and Aboul- Gheit, A.K., Hydroconversion of n-paraffins in light naphtha using $\mathrm{Pt} / \mathrm{Al}_{2} \mathrm{O}_{3}$ catalysts promoted with noble metals and/or chlorine. Applied Catalysis A: General, 205, 129 (2001).

4. Aboul-Gheit, A.K., The hydrogenation of aromatics on catalysts having their platinum, ruthenium and palladium replaced with rhenium. J. Appl. Chem. Biotechnol. 27, 121(1977).

5. Aboul-Gheit, A.K., Monoufy, M.F., El-Fadly , A.M., Sif El-Din, O.I. and Sultan, S.A., The selectivity of n-heptane isomerization on catalysts containing platinum and / or Chlorine on different supports. J. Chem. Technol. Biotechnol. 32 (1982)

6. Ali, L.I., Ali, A.G.A., Aboul-Fotouh, S.M. and Aboul-Gheit, A.K., App. Catal. A:General, 205, 129 (2001). .

7. Aboul-Gheit, A.K. and Ghoneim, Salwa A. W. Catalysis in the Petroleum naphtha catalytic reforming process. Recent Patents on Chemistry \& Technology of Fuels \& Oils, 44 4, 215 (2008).

8. Aboul-Gheit, A.K., Ghoneim, S.A. and Al-Owais, A. A., Effect of hydrothermal treatment and ammonium ion incorporation in platinum-mordenite catalysis for $\mathrm{n}$ hexane hydroconversion. Appl.Catal. A, 170, 277 (1998).

9. Corma, A., Serra, J. M. and Chica, Discovery of new paraffin isomerization catalysts based on $\mathrm{SO}_{4}{ }^{2-} / \mathrm{ZrO}_{2}$ and $\mathrm{WO}_{\mathrm{x}} / \mathrm{ZrO}_{2}$ applying combinatorial techniques. A Catal. Today, 81, 495 (2003).

10. Hwang, C. C. and Mou, C. Y., Comparison of the promotion effects on sulphated mesoporous zirconia catalysts achieved by alumina and gallium. Appl. Catal. A: General, 365, 173 (2009).

11. Jin, T., Yamaguchi, T. and Tanabe, K., Mechanism of acidity generation on sulfurpromoted metal oxides. J. Phys. Chem. 90, 4974 (1986).

12. Reddy, B. M. and Patil, M. K., Organic syntheses and transformations catalyzed by sulfated zirconia. Chem. Rev. 109, 2185 (2009).

13. Li, X. B., Nagaoka, K., Olindo, R. and Lercher, On the catalytic nature of $\mathrm{Mn} /$ sulphated zirconia for selective reduction of NO with methane. J. A.. J. Catal. 238, 39 (2006).

14. Prasetyoko, D., Ramli, Z., Endud, S. and Nur, H., TS-1 loaded with sulfated zirconia as bifunctional oxidative and acidic catalyst for transformation of 1-octene to 1,2-octanediol. J. Mol. Catal. A: Chemical. 241, 118 (2005).

Egypt. J. Chem. 55, No. 5 (2012) 
15. Li, X. B., Nagaoka, K., Simon, L. J., Olindo, R., Lercher, J. A., Hoffmann, A. and Sauer, J., Oxidative activation of n-butane on sulfated zirconia. J. Am. Chem. Soc. 59, 127 (2005).

16. Haouas, M., Walspurger, S., Taulelle, F. and Sommer, J., The initial stages of solid acid-catalyzed reactions of adsorbed propane. A mechanistic study by in situ MAS NMR. J. Am. Chem. Soc. 126, 599 (2004).

17. Al-Daous, M. A. and Stein, Preparation and catalytic evaluation of macroporous crystalline sulfated zirconium dioxide templated with colloidal crystals. A. Chem. Mater. 15, 2638 (2003).

18. Yadav, G. D. and Nair, Sulfated zirconia and its modified versions as promising catalysts for industrial processes. J. Microporous and Mesoporous Mater. 33,1 (1999).

19. Davis, B. H., Keogh, R. A. and Srinivasan, R., Sulfated zirconia as a hydrocarbon conversion catalyst. Catal. Today, 20, 219 (1994).

20. Hollstein, E. J., Wei, J. T. and Hsu, C. Y., Catalyst for hydrocarbon conversion and conversion process utilizing the same. US Patent, 918, 4, 041 (1990).

21. Travers and Christine, Petroleum Refining: Conversion Processes, Nov 12, Chapter 6, pp. (233-234) (2011).

22. Tichit, D., Coq, B., Amendarize, H. and Figuéras, F., One-step sol-gel synthesis of sulphated-zirconia catalysis. Catal. Lett. 38, 109 (1996).

23. Signoretto, M., Pinna, F., Strkul, G., Cerrato, G. and Mortera C., Platinum promoted zirconia-sulfate catalysts: One-pot preparation. Physical Properties and Catalytic Activity, Catalyst Letters, 36, 129 (1996).

24. Tran, M. T., Gnep, N. S., Szabo, G. and Guisnet, M., Infuence of the calcination temperature on the acidic and catalytic properties of sulphated zirconia. Appl Catal. A. Gen. 171, 207 (1998).

25. Corma, A., Juan, Rajadell, A. I. and Lopez Nieto, J. M., Influence of preparation conditions on the structure and catalytic properties of $\mathrm{SO}_{4}{ }^{2-} / \mathrm{ZrO}_{2}$ superacid catalysts. Appl. Catal. A. 116, 151(1994).

26. Sun, Y. Y., Zhu, L., Lu, H., Wang, R., Lin, S., Jiang, D. and Xiao, F. S., Sulfated zirconia supported in mesoporous materials. Appl.Catal. A. 237, 21 (2002). 
27. Matsuhashi, H., Tanaka, M., Nakamura, H. and Arata, K., Formation of acid sites in orderd pores of FMS-16 by modification with sulphated zirconia. Appl.Catal. A,208, 1 (2001).

28. Hua, W.M., Tang, Y., Yue, Y. H. and Gao, Z., Acidity enhancement of SEA mesoporous molecular sieve by modification with $\mathrm{SO}_{4}{ }^{2-} / \mathrm{ZrO}_{2}$. J. Mol. Catal. 170, 195 (2001).

29. Zhao, Y., Zeng, Y. and Tao, K., Crystal structure and acidity of solid acid $\mathrm{SO}_{4}{ }^{2-} /$ $\mathrm{ZrO}_{2}$ and its catalytic activity for isomerization of butane. Chinese J. Catal. 23, 168. (2002).

30. Stichert, W., Schüth, F., Kuba, S. and Knözinger, H., Monoclinic and tetragonal high surface area sulfated zircon as in butane isomerization: $\mathrm{CO}$ adsorption and catalytic results. J. Catal. 198, 277 (2001).

31. Haase, F., and Sauer, J., The surface structure of sulfated zirconia: periodic ab initio study of sulfuric acid adsorbed on $\mathrm{ZrO}_{2}$ (101) and $\mathrm{ZrO}_{2}$ (001). J. Am. Chem. Soc. 120, 13503 (1998).

32. Wang, X., Wang, H., Liu, Y., Liu, F., Yu, Y. and He, H. A., A direct sulfation method for introducing the transition metal cation $\mathrm{Co}^{2+}$ Into $\mathrm{ZrO}_{2}$ with little change in the Brønsted acid sites. J. Catal. 279, 301 (2011).

33. Biró, K., Figueras, F. and Békássy, S., Acylation of B15C5 crown ether by acetic anhydride in the absence of solvent, on sulfated zirconias prepared in different conditions. Appl. Catal. A: General, 229, 235 (2002).

34. Platero, E. E., Mentruit, M. P., Arean, C. O. and Zecchina, A FTIR studies on the acidity of sulfated zirconia prepared by thermolysis of zirconium sulphate. $J$. Catal. 162, 268 (1996).

35. Prasetyoko, D., Ramli, Z., Endud, S. and Nur, H., Structural and acidity studies of sulfated zirconia prepared from zirconium sulphate. Majalah IPTEK-ITS. 17, 40 (2006).

36. Cornelli, R. A., Vera, E. R. and Parera, J. M., Influence of $\mathrm{ZrO}_{2}$ crystalline structure and sulfate ion concentration on the catalytic activity of $\mathrm{SO}_{4}^{2-} \mathrm{ZrO}_{2}$.J. Catal. 151, 96 (1995).

37. Sohn, J. R. and Lee, S. Y., High catalytic activity of $\mathrm{NiO}-\mathrm{ZrO}_{2}$ modified with $\mathrm{WO}_{3}$ for ethylene dimerization. Appl. Catal. A: Gen. 164,127 (1997). 
38. Sohn, J. R., Kwon, T. D. and Kim, S. B., Characterization of zirconium sulfate supported on zirconia and activity for acid catalysis. Korean Chem. Soc. 22, 1309 (2001).

39. Sarzanini, C., Sacchero, G., Pinna, F., Signoretto, M., Cerrato, G. and Morterra, C. , Amount and nature of sulfates at the surface of sulphate-doped zirconia catalysts. J. Mater. Chem. 5, 353 (1995).

40. Li, N., Wang, A., Zheng, M., Wang, X., Cheng, R. and Zhang, T., Probing into the catalytic nature of $\mathrm{Co} /$ sulfated zirconia for selective reduction of $\mathrm{NO}$ with methane. $J$. Catal. 225, 307 (2004).

41. Komarov, V.S. and Sinilo, M.F., IR-spectroscopic investigation of the acid properties of the surface of zirconium oxide modified by sulfate ions. Kinet. Katal. 29, 605 (1988).

42. Scalona Platero, E. and Penarroya Mentruit, M., IR characterization of sulfated zirconia derived from zirconium sulphate. Catal. Lett. 30, 31 (1995).

43. Babou, F., Coudurier, G. and Vedrine, J.E., Acidic properties of sulfated zirconia: An infrared spectroscopic study. J. Catal. 152, 341 (1995).

44. Rosenberg, D. J., Bachiller, B. B., Dines, T. J. and Anderson, J. A., Nature of surface sulfate species and the generation of active sites on silica-zirconia mixedoxide catalysts. J. Phys. Chem. B. 107, 6526 (2003).

45. Sun, Y., Ma, S., Du, Y., Yuan, L., Wang, S., Yang, J., Deng, F. and Xiao, F. S., Solvent-free preparation of nanosized sulfated zirconia with Brønsted acidic sites from a simple calcinations. J. Phys. Chem. B. 109, 2567 (2005).

46. Huang, Y. Y., McCarthy, T. J. and Sachlter, W. M. H., Preparation and catalytic testing of mesoporous sulfated zirconium dioxide with partially tetragonal wall structure. Appl. Catal. A. Gen. 5, 148 (1996).

47. Zhou, X. L., Yu, G. X., Tang, C., Li, C. L., Wang, J. A., Novaro, O., Llanos, M. E. and Cortés-Jácome, M. A., On the role of calcination. temperature in $\mathrm{Pt}_{-} \mathrm{SO}_{4}{ }^{-}$ ${ }^{2} / \mathrm{ZrO}_{2}-\mathrm{Al}_{2} \mathrm{O}_{3}$ preparation and catalytic behavior during the n-hexane hydroisomerization. Catal. Lett. 124, 277 (2008).

48. Biro, K., Figueras, F., Marquez Alvarez, C., Bekassy, S. and Valyon, J., $7^{\text {th }}$ Europeun Symposiumon on Thermal Analysis Calorimetry, Balatonfured (1998).

49. Biró, K., Figueras, F., Márquez ALvarez, C., Békássy, S. and Valyon, J., Characterization of sulfated zirconias by DTA-TG and DRIFT spectroscopy. $J$. Therm. Anal. Cal. 56, 345 (1999). 
50. Hua, W., Xia, Y., Yue, Y. and Gao, Z., Promoting effect of Al on ZO/MO catalysts. J. Catal. 196, 104 (2000).

51. Das, D., Mishra, H. K., Parida, K. M. and Dalai, A. K., Preparation, physicchemical characterization and catalytic activity of sulphated $\mathrm{ZrO}_{2}-\mathrm{TiO}_{2}$ mixed oxides. J. Mol. Catal. A.189, 271 (2000).

52. Vera, C. R., Pieck, C. L., Shimizu, K. and Parera, Tetragonal structure anionic vacancies and catalytic activity of $\mathrm{SO}_{4}{ }^{2-}-\mathrm{ZrO}_{2}$ catalysts for n-butane isomerisation. $J$. M. Appl. Catal. A. 230, 137 (2002).

53. Hsu, Y. S., Wang, Y. L. and Ko , A. N. J., Effect of sulfation of zirconia on catalytic performance in the dehydration of aliphatic alcohols. Chinese Chem. Soc. 56, 314 (2009).

54. Signoretto, M., Melada, S., Pinna, F., Polizzi, S., Cerrato, G. and Mortera, C., Micro. Meso. Mater. 81, 19 (2005).

55. Keogh, R.A., Sparks, D., Hu, J., Wender, I., Tierney, J.W., Wang, W. and Davis, B.H., Hydroisomerization and hydrocracking of n-hexadecane over a platinumpromoted sulfated zirconia catalyst. Energy \& Fuels, 8 (3), 755 (1994).

56. Li, B.H. and Gonzalez, R.D., Ind. Eng. Chem. Res. 35, 9, 4 (1996).

57. Li, B.H. and Gonzalez, R.D., TGA FT-IR studies of the deactivation of sulfated zirconia catalysts. Appl. Catal. A: Gen.165 (1-2), 291(1997).

(Received 1/10/2012;

accepted 6/11/2012) 


\section{الزركونيا المكبرتة كحفاز لأزمرة البتان العادى عند درجات حرارة}

منخفضة

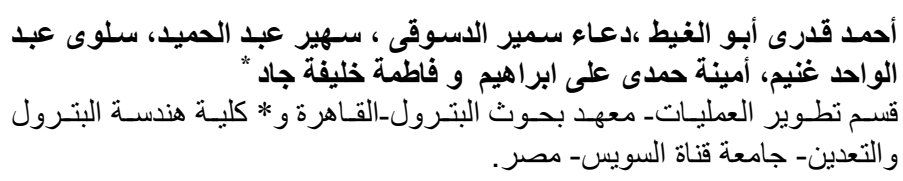

تم تحضير مجموعة من الحفاز ات غير التقليدية المحتوية على كبريتات الزركونيا

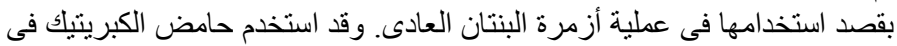

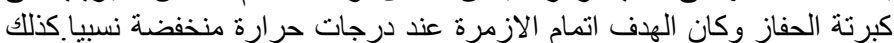

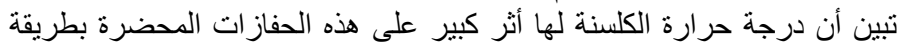

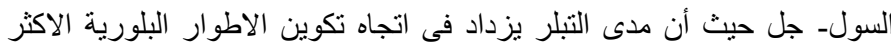

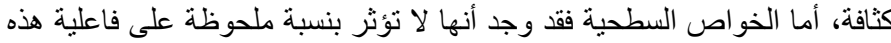

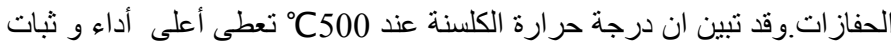

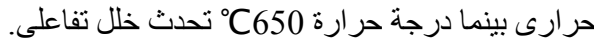

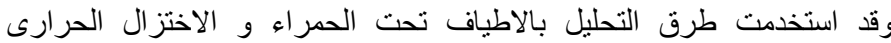

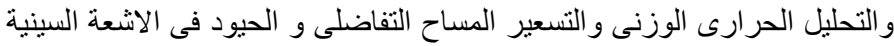

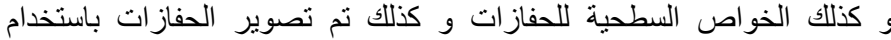
الميكروسكوب الالكثرونى النافذ. 